Supporting Information for

\title{
Interfacial Drawing: Roll-to-Roll Coating of Semiconducting Polymer and Barrier Films onto Plastic Foils and Textiles
}

Rory Runser, ${ }^{\dagger}$ Samuel E. Root, ${ }^{\dagger}$ Derick E. Ober, Kartik Choudhary, Alex X. Chen, Charles

Dhong, Armando D. Urbina, Darren J. Lipomi.*

Department of NanoEngineering, University of California, San Diego, 9500 Gilman Drive, Mail Code 0440, La Jolla, California 92093-0448, United States

${ }^{\dagger}$ Authors contributed equally

*Correspondence to: dlipomi@eng.ucsd.edu 

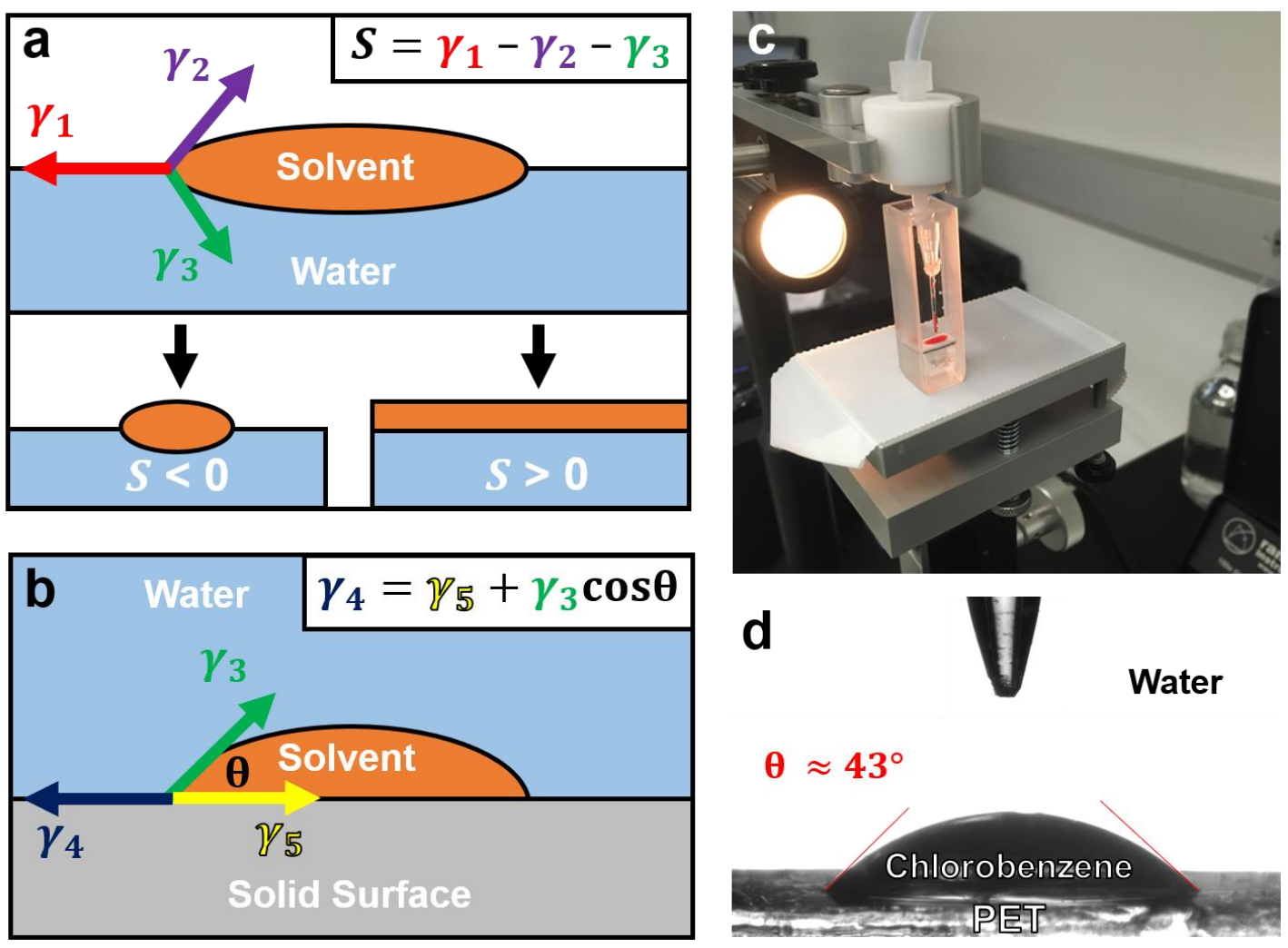

Figure S1: Physics of solution spreading. (a) Schematic illustration of interfacial drawing as governed by the spreading coefficient of solvent. (b) Schematic illustration of underwater contact angle measurements. (c) Photograph of our setup for measuring underwater contact angles, showing a quartz cuvette filled with water, an interchangeable surface (PET, PTFE, or $\mathrm{SiO}_{2}$ ), and a needle dispenser. A small amount of P3HT was dissolved in the solvents to aid visualization. (d). Photograph of underwater contact angle measurement. Water contact angles were measured using a Rame Hart contact angle goniometer. 

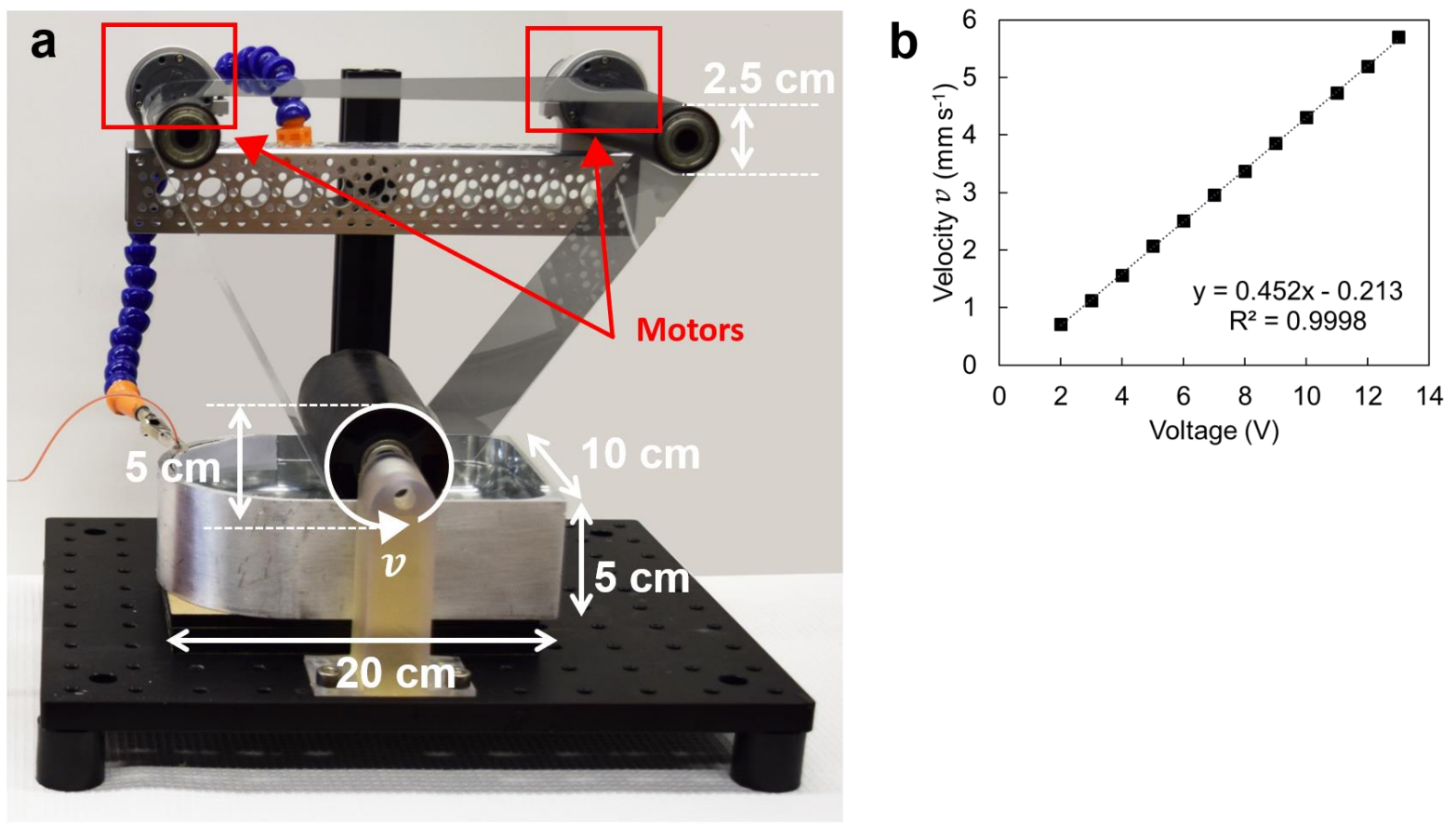

Figure S2: System dimensions and control scheme. (a) Diagram of our setup. Note that only the top two rollers are controlled by the motors, and the bottom roller moves due to friction between itself and the flexible PET sheet. Motors are controlled to a voltage actuator, which could be varied to adjust the speed of rotation. (b) Calibration between applied voltage to motors and linear velocity of PET loop. 
Table S1: Underwater contact angles for relevant solvents on Teflon (PTFE), PET, and glass surfaces. Water contact angles were measured using a Rame Hart contact angle goniometer.

\begin{tabular}{ccc}
\hline Solvent & Solid Surface & Underwater Contact Angle $\left(^{\circ}\right)$ \\
\hline Chloroform & Teflon & 2.63 \\
Chlorobenzene & Teflon & 14.6 \\
o-Dichlorobenzene & Teflon & 9.4 \\
Chloroform & PET & 48.5 \\
Chlorobenzene & PET & 43.5 \\
o-Dichlorobenzene & PET & 45.2 \\
Chloroform & Glass & 88.9 \\
Chlorobenzene & Glass & 141.0 \\
o-Dichlorobenzene & Glass & 146.0 \\
\hline
\end{tabular}

Table S2: Surface tension values for relevant materials interactions.

\begin{tabular}{cccc}
\hline Parameter & Materials & $\begin{array}{c}\text { Surface Tension } \\
{\left[\mathbf{m ~ N ~ m}^{-1}\right]}\end{array}$ & Reference \\
\hline$\gamma_{1}$ & Water - air & 72.8 & {$[1]$} \\
$\gamma_{2}$ & Chloroform - air & 27.1 & {$[2]$} \\
$\gamma_{2}$ & Chlorobenzene - air & 33.6 & {$[3]$} \\
$\gamma_{2}$ & o-Dichlorobenzene - air & 37 & {$[4]$} \\
$\gamma_{3}$ & Chloroform - water & 32.8 & {$[2]$} \\
$\gamma_{3}$ & Chlorobenzene - water & 37.4 & {$[3]$} \\
$\gamma_{3}$ & o-Dichlorobenzene - water & 40 & {$[4]$} \\
$\gamma_{4}$ & Teflon - water & 16.9 & {$[5]$} \\
$\gamma_{4}$ & PET - water & 39.0 & {$[5]$} \\
\hline
\end{tabular}

Table S3: Calculated spreading parameters for relevant solvents (calculated from the equation in Figure S2a). $O$-dichlorobenzene cannot be used for interfacial drawing due to its positive spreading parameter.

\begin{tabular}{cc}
\hline Solvent & Spreading Parameter $\boldsymbol{S}\left[\mathrm{mN} \mathrm{m}^{-1}\right]$ \\
\hline Chloroform & 12.1 \\
Chlorobenzene & 1.8 \\
o-Dichlorobenzene & -4.2 \\
\hline
\end{tabular}




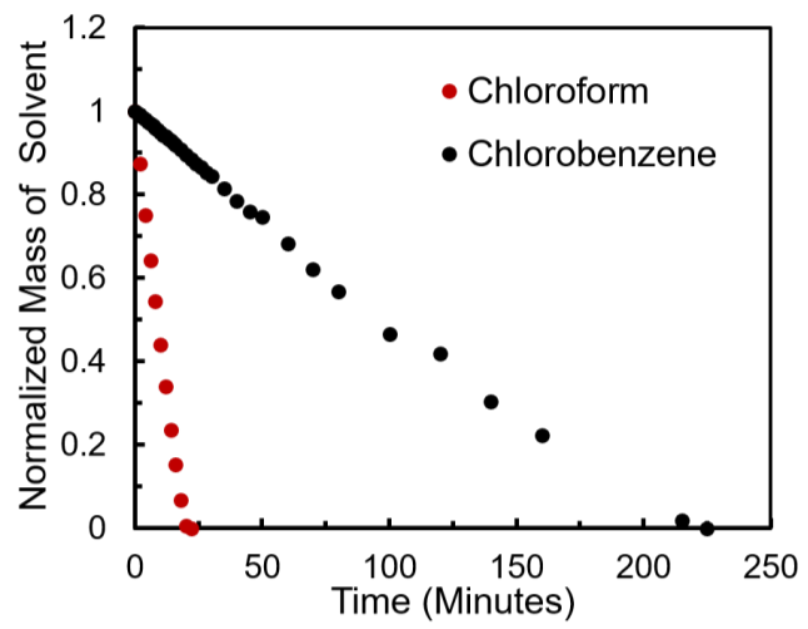

Figure S3: Determination of evaporative mass transfer coefficients for relevant solvents. A known mass of solvent was placed into a petri dish of known area, and the change in mass due to evaporation was recorded over time. This rate of mass transfer was converted to a linear velocity using the density of the solvents.

Table S4: Evaporative mass transfer coefficients for relevant solvents. The high volatility of chloroform resulted in brittle films when polymers were processed from a chloroform solution, due to extremely rapid drying.

\begin{tabular}{cc}
\hline Solvent & $\begin{array}{c}\text { Evaporative mass transfer } \\
\text { coefficient }\left[\mathrm{cm} \mathrm{s}^{-1}\right]\end{array}$ \\
\hline Chloroform & $1.2 \times 10^{-4}$ \\
Chlorobenzene & $1.2 \times 10^{-5}$ \\
\hline
\end{tabular}


Table S5: Viscosity data for solvents and polymer solutions. Solution viscosities were measured using a RheoSense microviscommeter.

\begin{tabular}{cccc}
\hline Material & Solvent & $\begin{array}{c}\text { Concentration } \\
{\left[\mathrm{mg} \mathrm{m}^{-1}\right]}\end{array}$ & $\begin{array}{c}\text { Viscosity [MPa } \\
\text { s] }\end{array}$ \\
\hline- & $\mathrm{CB}$ & - & 0.929 \\
P3HT & $\mathrm{CB}$ & 10 & 2.09 \\
P3HT & $\mathrm{CB}$ & 20 & 3.35 \\
P3HT & $\mathrm{CB}$ & 30 & 5.19 \\
P3HT & $\mathrm{CB}$ & 40 & 9.91 \\
& $\mathrm{CHCl}$ & & 0.79 \\
- & $\mathrm{CHCl}_{3}$ & - & 1.94 \\
P3HT & $\mathrm{CHCl} 3$ & 20 & 4.45 \\
P3HT & $\mathrm{CB}$ & 40 & 2.86 \\
PTB7 & $\mathrm{CB}$ & 10 & 4.64 \\
\hline J51:N2200 & & 20 & \\
\hline
\end{tabular}



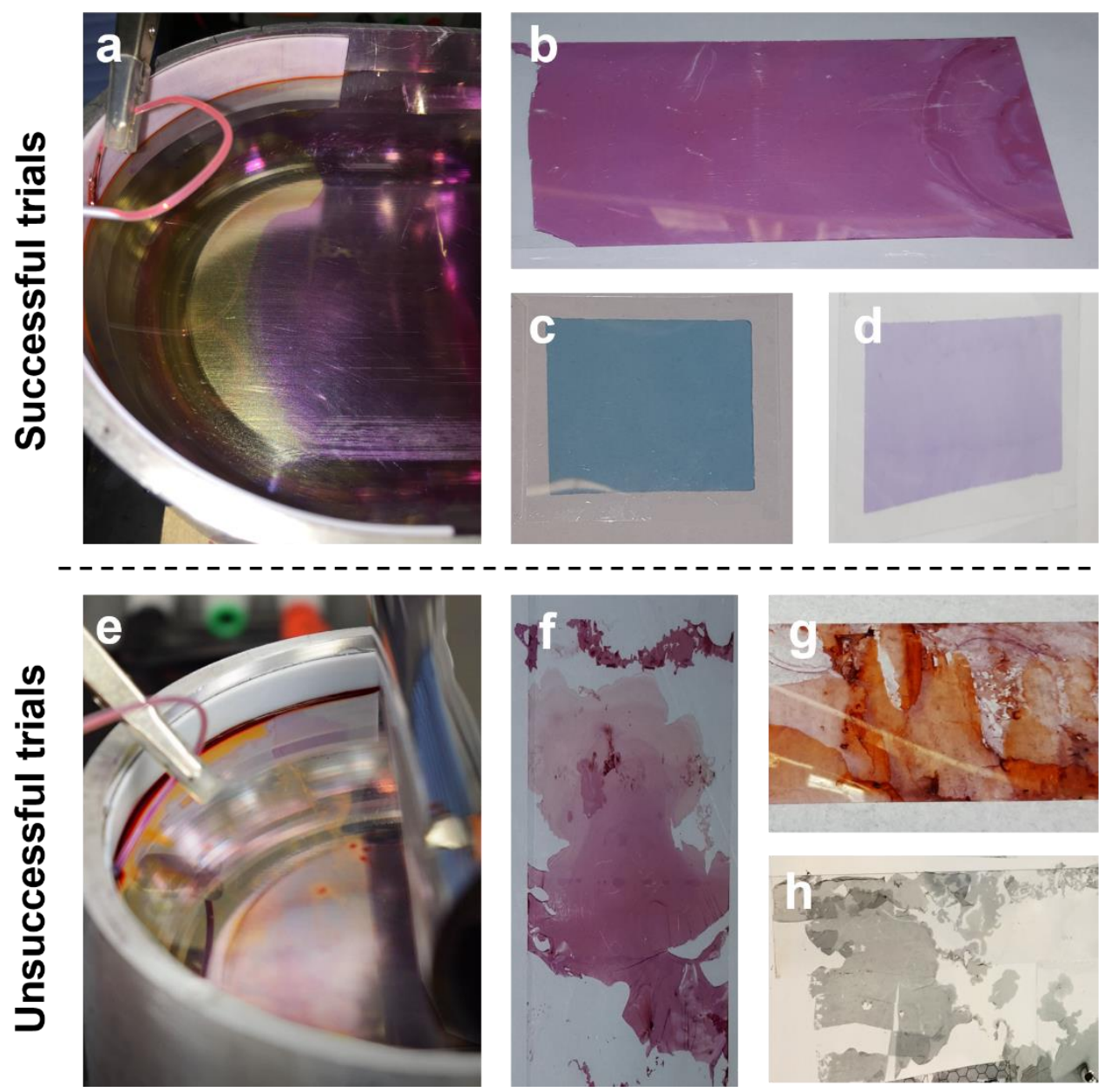

Figure S4: Limitations and important considerations of interfacial drawing. (a-d) Photos of successful operation, showing (a) cohesive film formation on the water bath; crack-free films of (b) P3HT with 1 vol\% DIO, (c) PTB7, and (d) J51:N2200. (e-h) Photos of unsuccessful operation, showing (e) uneven film drying on the water bath when the trough was not adequately cleaned between trials, and (f) corresponding film of P3HT; cracked films of (g) P3HT:PC ${ }_{61} \mathrm{BM}(1: 1 \mathrm{w} / \mathrm{w})$, and (h) PTB7:PC 61 BM (1:1 w/w), showing substantial cracking upon addition of fullerenes in order to make a bulk heterojunction organic solar cell (despite thoroughly cleaning trough between trials). 
Table S6: Summary of operation process parameters for all trials depicted in Figure 3. All trials utilized chlorobenzene as a solvent. The overflow is defined as $\frac{Q C}{\rho_{p} v w H}$ (i.e. a ratio the rate of polymer injection onto the water bath to the rate of polymer accumulation on the solid substrate). An overflow parameter of 1.0 indicates the process is occurring at steady-state; an overflow parameter of $>1$ indicates that an excess of polymer solution is accumulating along the wall edge meniscus. This term yields the same information as equation (1) in the main text, but in a dimenisionless form (equation (1) gives a rate of accumulation, in $\mathrm{mg} \mathrm{min}^{-1}$, of polymer solution along the wall edge meniscus).

\begin{tabular}{|c|c|c|c|c|c|c|c|}
\hline Material & $\begin{array}{c}C \\
\left(\mathrm{mg} \mathrm{mL}^{-1}\right)\end{array}$ & $\begin{array}{c}Q \\
\left(\mu \mathrm{L} \text { min }^{-1}\right)\end{array}$ & $\begin{array}{c}w \\
(\mathrm{~cm})\end{array}$ & $\begin{array}{c}\rho_{p} \\
\left(\mathrm{~g} \mathrm{~mL}^{-1}\right)\end{array}$ & $\begin{array}{c}v \\
\left(\mathrm{~mm} \mathrm{~s}^{-1}\right)\end{array}$ & $\begin{array}{c}\boldsymbol{H} \\
(\mathrm{nm})\end{array}$ & Overflow \\
\hline Р3НТ & 5 & 40 & 10 & 1.1 & 2.05 & $6.9 \pm 1.8$ & 2.1 \\
\hline Р3НТ & 10 & 40 & 10 & 1.1 & 2.05 & $20.0 \pm 4.3$ & 1.5 \\
\hline Р3HT & 20 & 40 & 10 & 1.1 & 2.05 & $39.3 \pm 2.2$ & 1.5 \\
\hline Р3НT & 30 & 40 & 10 & 1.1 & 2.05 & $59.9 \pm 2.3$ & 1.5 \\
\hline Р3НT & 40 & 40 & 10 & 1.1 & 2.05 & $81.0 \pm 8.3$ & 1.5 \\
\hline Р3НТ & 20 & 40 & 10 & 1.1 & 2.05 & $34.1 \pm 2.2$ & 1.7 \\
\hline Р3НT & 20 & 40 & 10 & 1.1 & 2.95 & $26.2 \pm 1.8$ & 1.6 \\
\hline Р3НT & 20 & 40 & 10 & 1.1 & 3.85 & $29.1 \pm 2.3$ & 1.1 \\
\hline Р3НТ & 20 & 40 & 10 & 1.1 & 4.75 & $26.3 \pm 1.4$ & 1.0 \\
\hline Р3НТ & 20 & 40 & 10 & 1.1 & 5.65 & $20.8 \pm 1.7$ & 1.0 \\
\hline Р3НТ & 10 & 10 & 10 & 1.1 & 2.05 & $11.3 \pm 5.1$ & 0.7 \\
\hline Р3НТ & 10 & 20 & 10 & 1.1 & 2.05 & $14.9 \pm 3.9$ & 1.0 \\
\hline Р3НТ & 10 & 40 & 10 & 1.1 & 2.05 & $19.5 \pm 2.2$ & 1.5 \\
\hline Р3НТ & 10 & 60 & 10 & 1.1 & 2.05 & $19.7 \pm 13.2$ & 2.3 \\
\hline Р3HT & 10 & 80 & 10 & 1.1 & 2.05 & $20.6 \pm 8.4$ & 2.9 \\
\hline PTB7 & 5 & 40 & 10 & 1.1 & 2.05 & $12.8 \pm 0.3$ & 1.2 \\
\hline PTB7 & 10 & 40 & 10 & 1.1 & 2.05 & $20.6 \pm 0.1$ & 1.4 \\
\hline PTB7 & 20 & 40 & 10 & 1.1 & 2.05 & $34.2 \pm 0.9$ & 1.7 \\
\hline PTB7 & 30 & 40 & 10 & 1.1 & 2.05 & $45.3 \pm 4.9$ & 2.0 \\
\hline PTB7 & 40 & 40 & 10 & 1.1 & 2.05 & $56.4 \pm 0.9$ & 2.1 \\
\hline J51:N2200 & 4 & 40 & 10 & 1.1 & 2.05 & $8.2 \pm 1.1$ & 1.4 \\
\hline J51:N2200 & 8 & 40 & 10 & 1.1 & 2.05 & $11.6 \pm 0.7$ & 2.0 \\
\hline J51:N2200 & 12 & 40 & 10 & 1.1 & 2.05 & $17.5 \pm 0.4$ & 2.0 \\
\hline J51:N2200 & 16 & 40 & 10 & 1.1 & 2.05 & $27.0 \pm 1.1$ & 1.8 \\
\hline J51:N2200 & 21 & 40 & 10 & 1.1 & 2.05 & $28.0 \pm 1.3$ & 2.2 \\
\hline
\end{tabular}




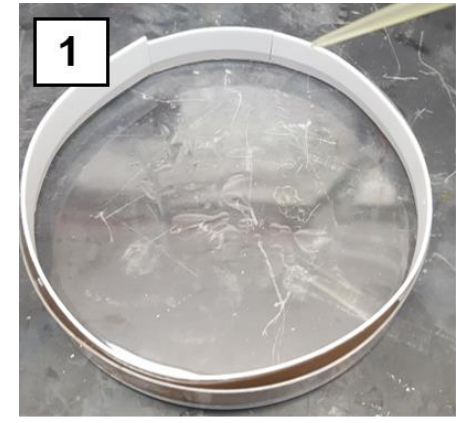

Clean water bath

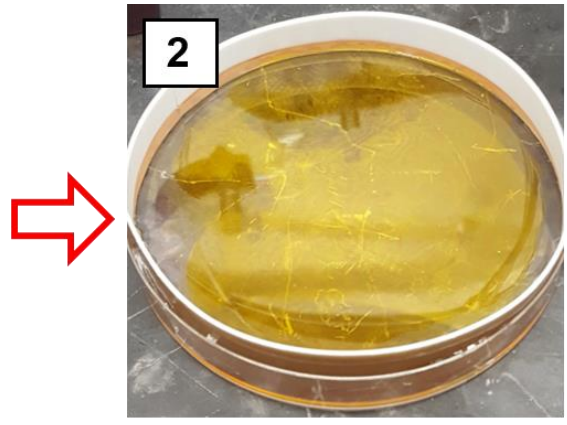

Solution Spreads

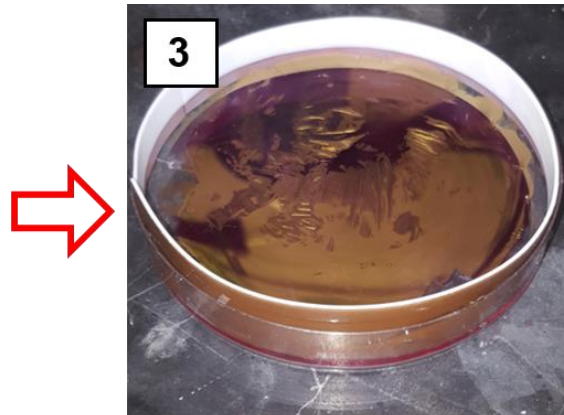

Solution dries

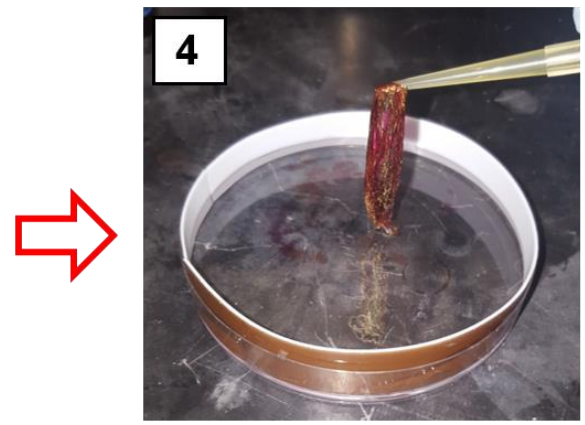

Remove dry film

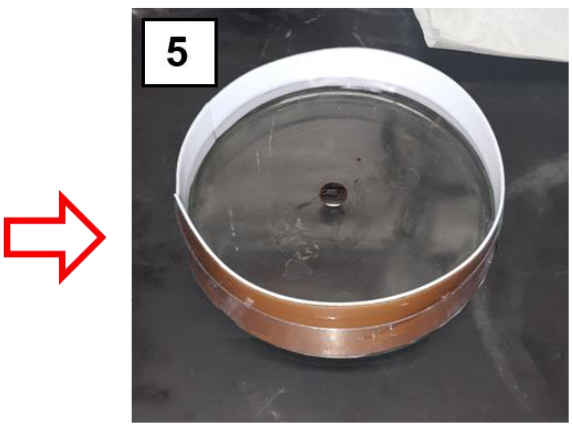

New solution doesn't spread

Figure S5: Effect of water bath contamination on subsequent solution spreading for a P3HT solution in CB. Schematic was captured in a petri dish rimmed with Teflon so as to mimic the interfacial drawing setup while aiding visualization and photography.

Table S7: Water contact angle for the interfacial drawing water bath before and after running a trial. Water was carefully gathered from the surface of the water bath using a syringe, and contact angles were measured on Teflon (3M 300LSE), using a Rame Hart contact angle goniometer.

\begin{tabular}{cc}
\hline Water Type & Contact Angle on Teflon \\
\hline Before trial & $109.2 \pm 3.4^{\circ}$ \\
After trial & $115.3 \pm 3.2^{\circ}$ \\
\hline
\end{tabular}



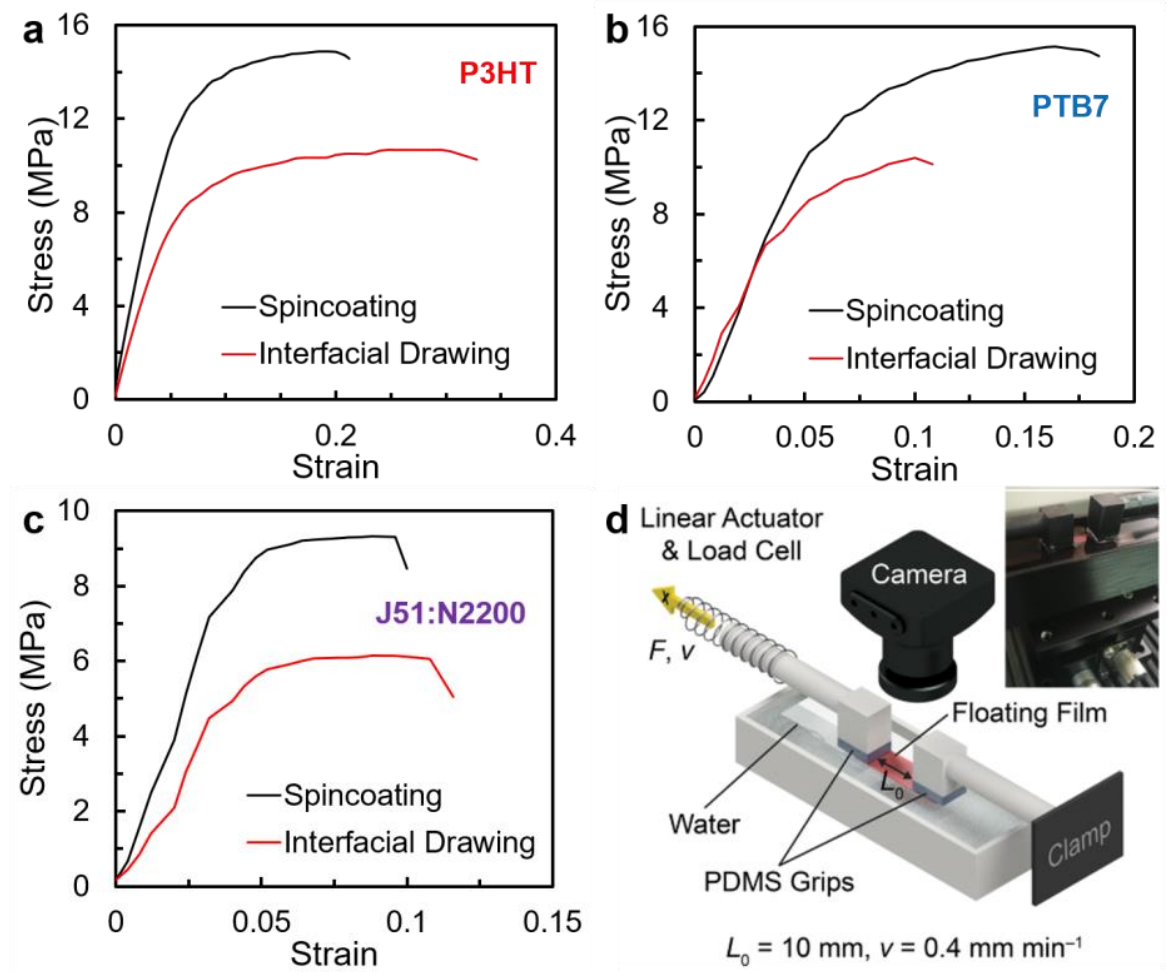

Figure S6: Representative stress-strain curves of (a) P3HT, (b) PTB7, and (c) J51:N2200, fabricated via spincoating and via interfacial drawing. (d) Schematic of film-on-water uniaxial tensile test used to generate these curves (figure reproduced with permission from Alkhadra, et $\mathrm{l}^{6}$; procedure developed by Kim, et $\mathrm{al}^{7}$ ). To prepare samples, glass slides were coated with a watersoluble layer of PEDOT:PSS (Clevios PH1000, applied via spincoating at $1000 \mathrm{rpm}$ for 3 minutes and annealed in air at $150^{\circ} \mathrm{C}$ for $15 \mathrm{~min}$ ). Next, polymer solution was applied to afford a thickness of $\sim 100-150 \mathrm{~nm}$. Then, slides were scored into rectangles, and slowly lowered into a water bath. The resulting free-floating polymer film was adhered to PDMS grips on a linear actuator attached to a force gauge. To obtain plots of force versus displacement, films were uniaxially strained at a rate of approximately $6.67 \times 10-4 \mathrm{~s}^{-1}\left(\mathrm{~L}_{0}=10 \mathrm{~mm}\right)$ until the test was terminated. The elastic modulus was estimated as the slope of the linear regime of the stress-strain curve. The fracture strain was reported as the strain at failure. In order to prepare films made via interfacial drawing, a modified procedure was used, as glass slides attached to our roll-to-roll apparatus caused the film to tear. Instead, a small volume of polymer solution was deposited onto a water bath in a petri dish and allowed to dry, after which a glass slide was stamped into the film. For PTB7 and J51:N2200 films, a small enclosure was added over the petri dish to ensure a more uniform film formed. We acknowledge that this process is not identical to interfacial drawing; however, the rapid rate and directional nature of solvent drying (the solvent dries radially inward) made it a good proxy for generating films for tests which require a rigid substrate. 

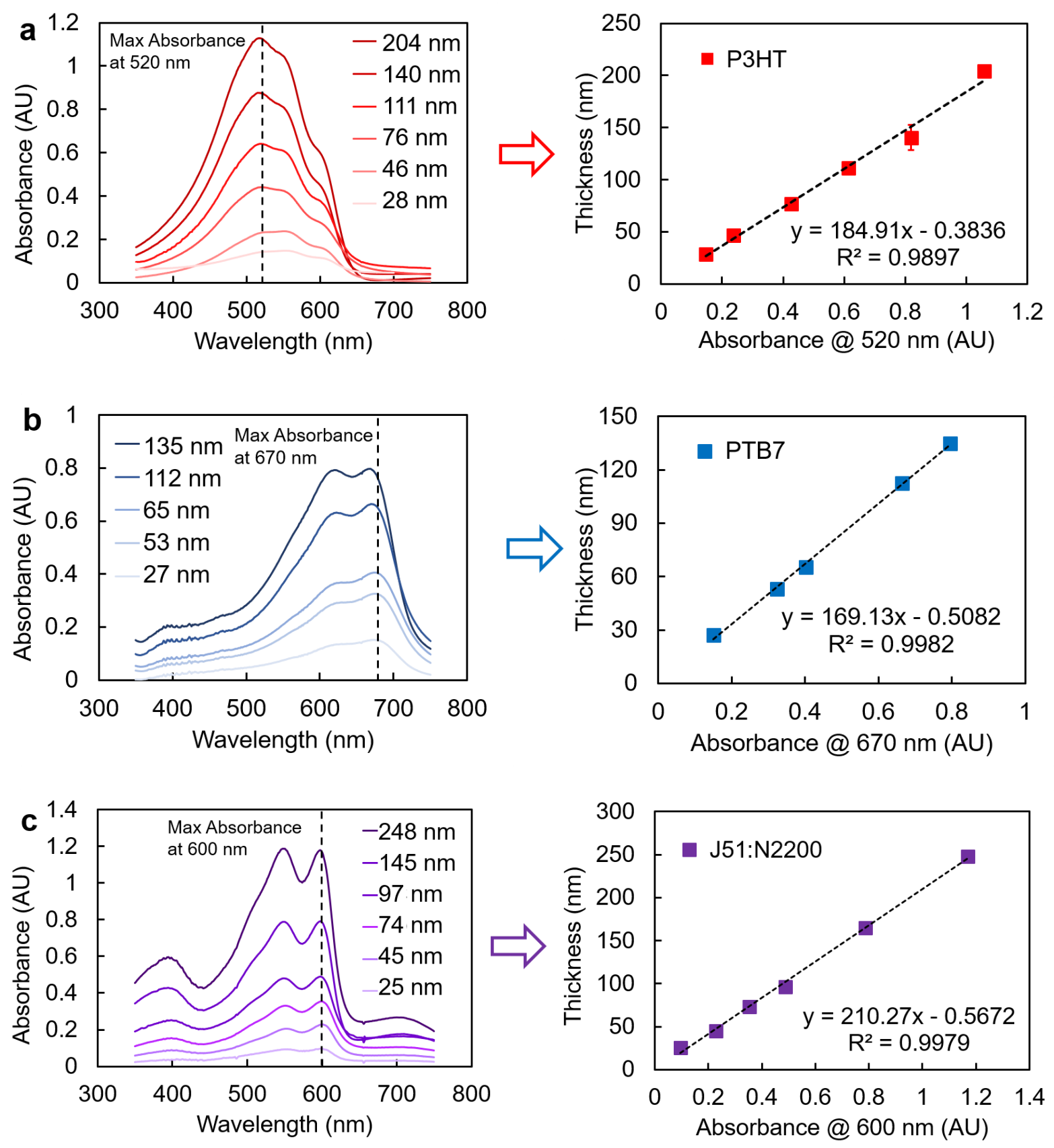

Figure S7: Thickness versus max absorbance (via UV-vis) calibration curves for (a) P3HT, (b) PTB7, and (c) J51:N2200. 


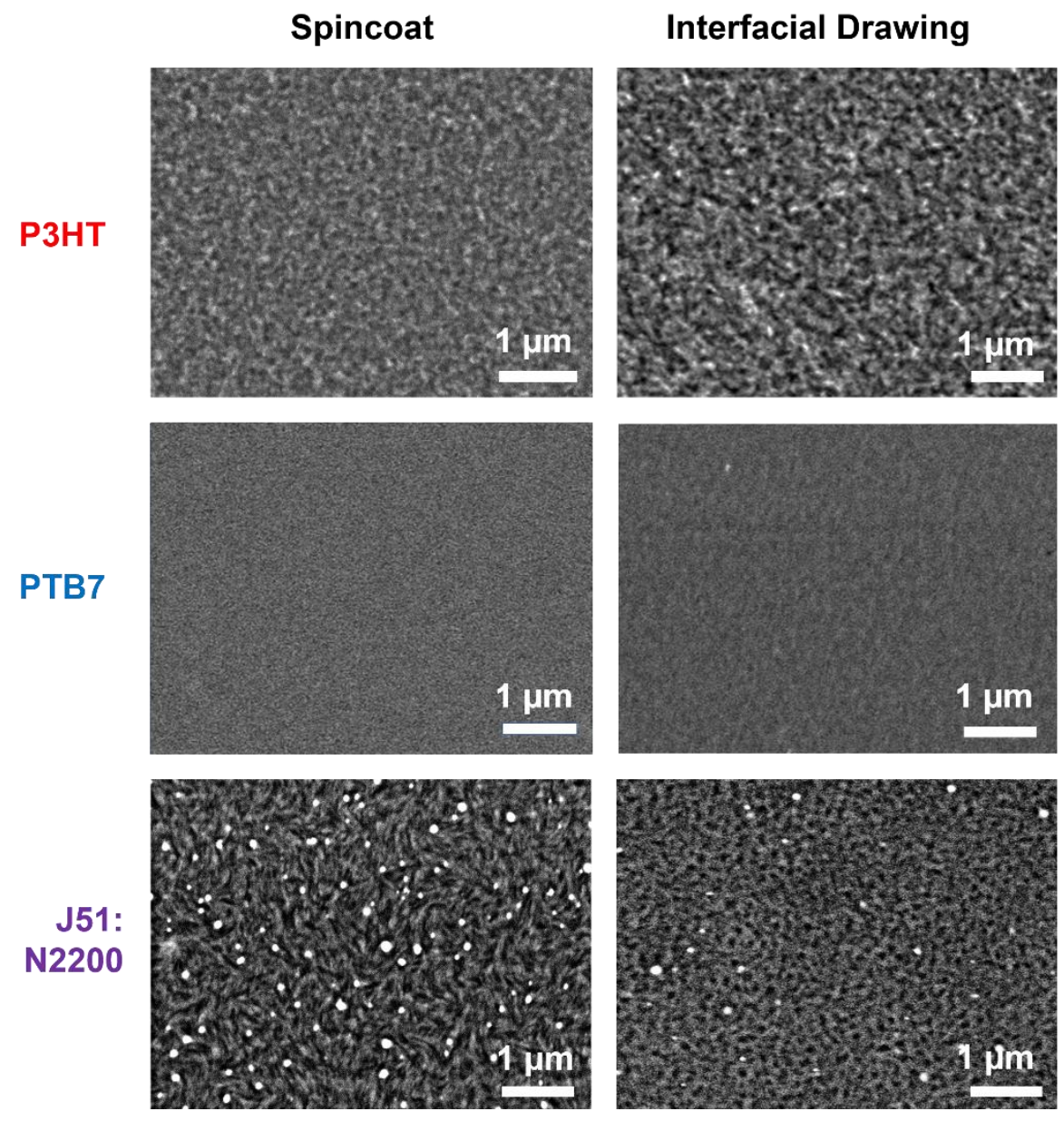

Figure S8: SEM images of films of P3HT, PTB7, and J51:N2200. Samples were prepared on a 1 $\mathrm{cm}^{2}$ silicon wafer. For the samples prepared by interfacial drawing, the Si wafer was attached to the PET roll via double-sided tape. SEM images were taken using a Zeiss Sigma 500 at $2 \mathrm{kV}$. 


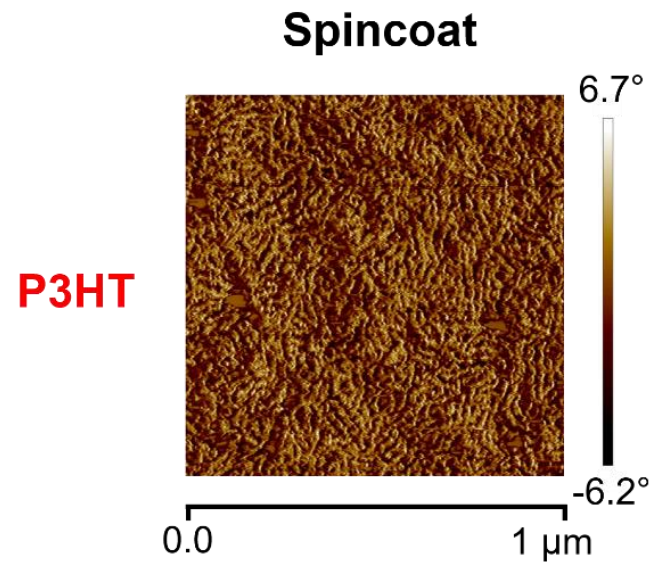

\section{Interfacial Drawing}
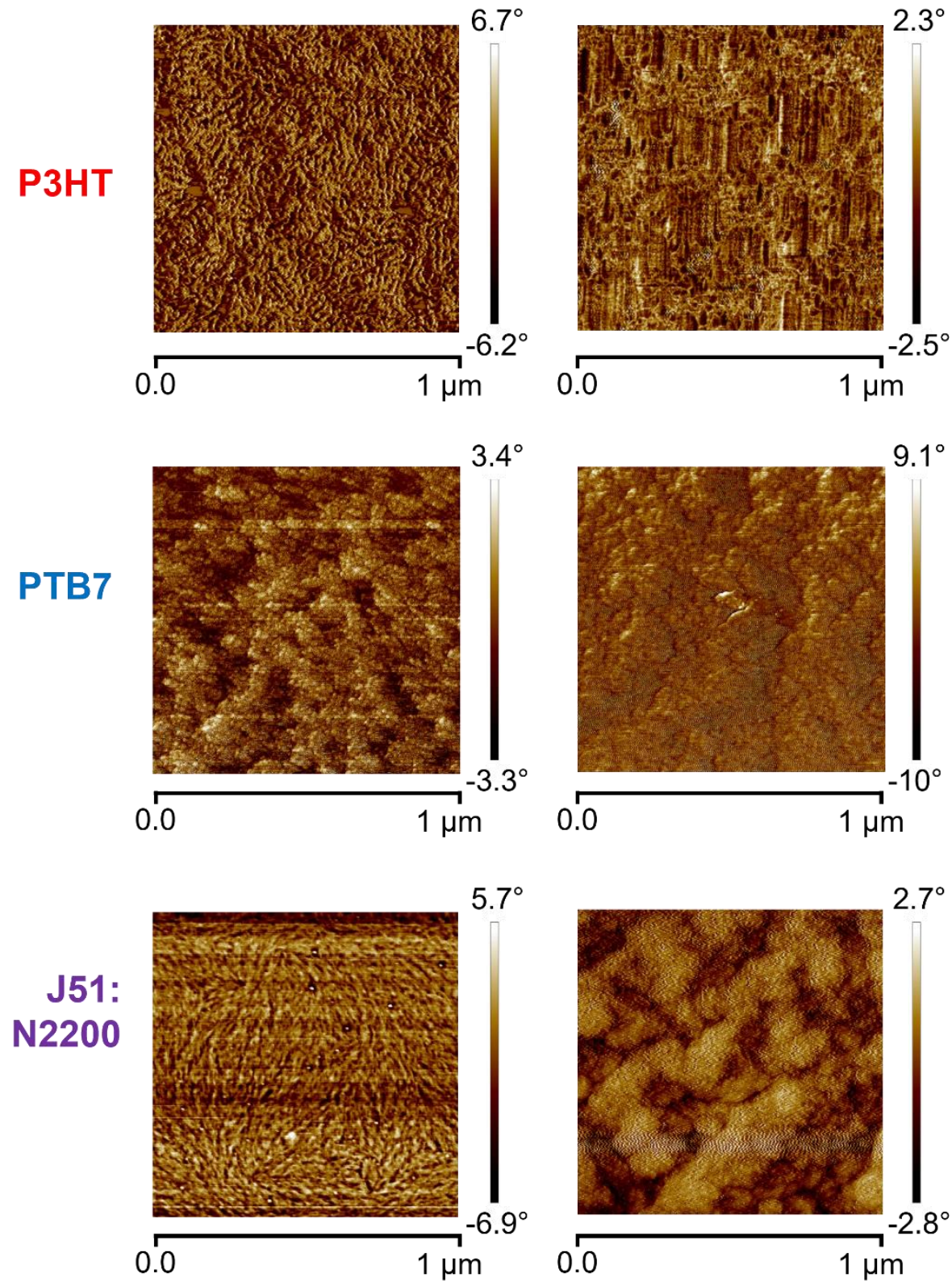

Figure S9: AFM images of films of P3HT, PTB7, and J51:N2200. The same samples were used for imaging on both SEM and AFM. Samples were imaged using a Veeco Surface Probe Microscope in non-contact tapping mode and analyzed using Nanoscope software 

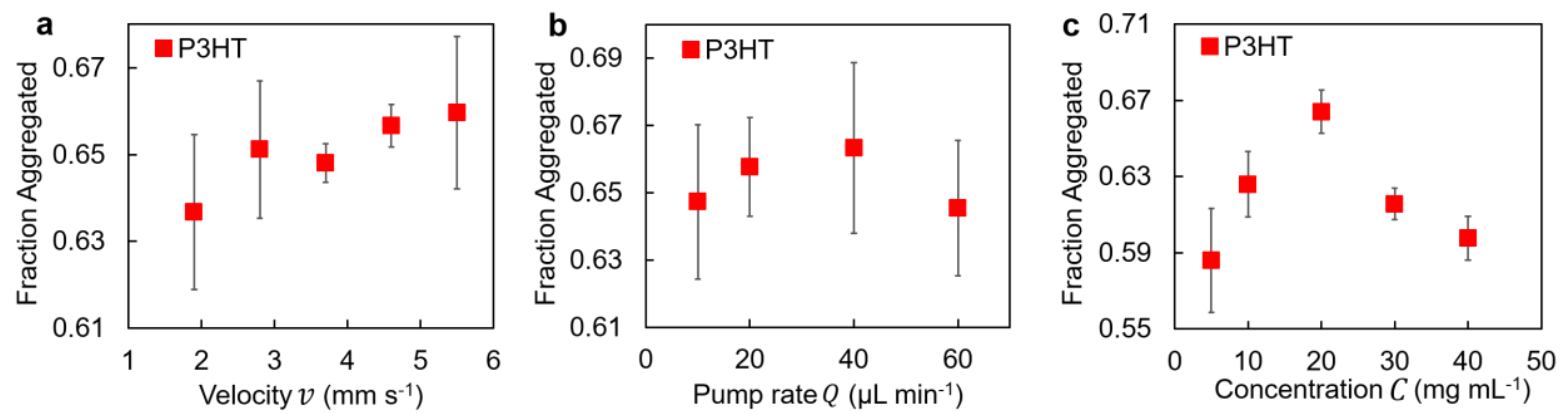

Figure S10: H-aggregate analysis of P3HT films. Further details of the analysis method are provided by Spano, et al. ${ }^{8}$ 


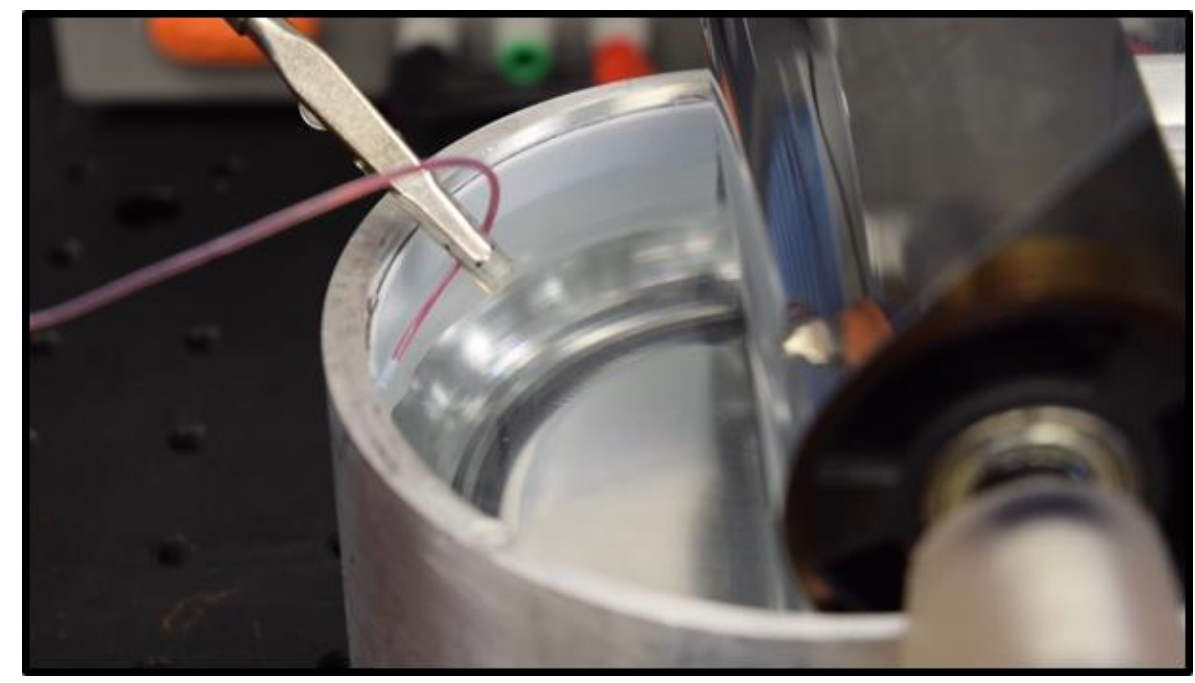

Movie S-M1: Video showing startup and steady-state operation of Interfacial Drawing, using a P3HT solution in chlorobenzene. This video may be downloaded separately or viewed online at the following link: https://youtu.be/JIu22xDYecQ

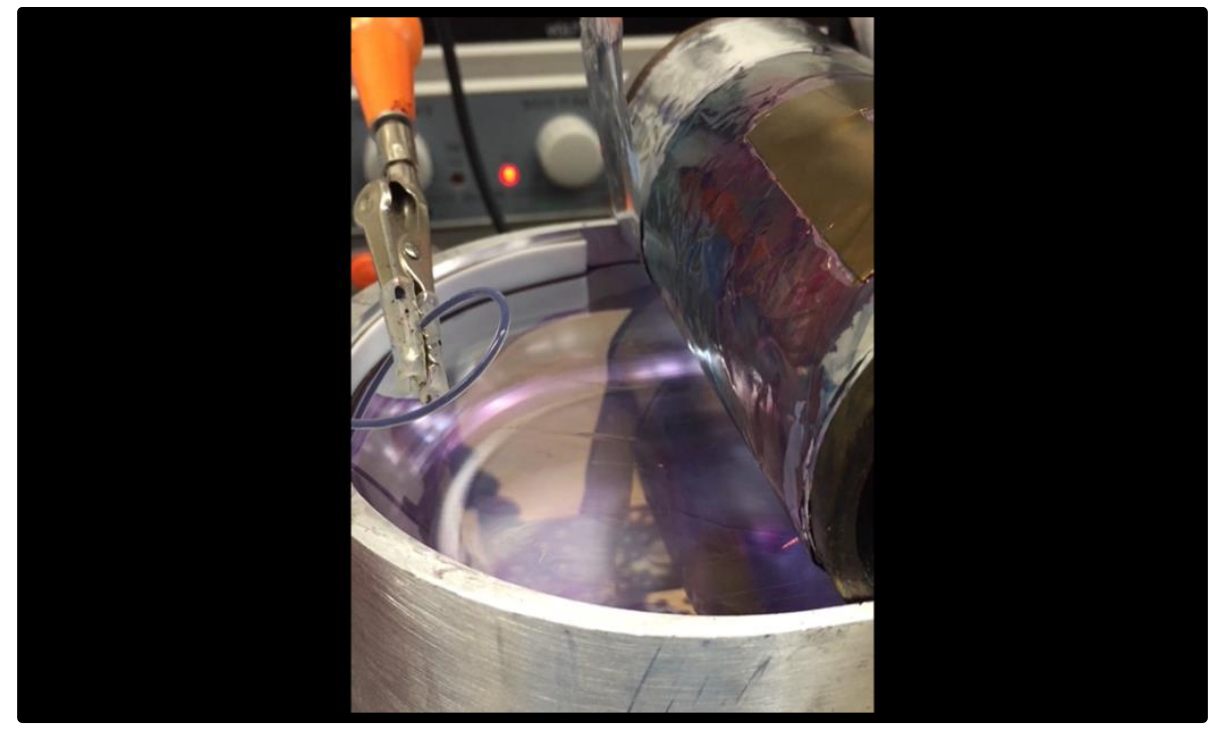

Movie S-M2: Video showing film breaking towards the end of a trial of Interfacial Drawing, using a J51:N2200 solution in chlorobenzene. This video may be downloaded separately or viewed online at the following link: https://youtu.be/P13aQTdiT5s (breakage occurs at 0:42). 


\section{References}

(1) The Engineering Toolbox. Surface Tension. https://www.engineeringtoolbox.com/surfacetension-d_962.html.

(2) National Library of Medicine. Compound Summary: Chloroform. https://pubchem.ncbi.nlm.nih.gov/compound/chloroform.

(3) National Library of Medicine. Compound Summary: Chlorobenzene https://pubchem.ncbi.nlm.nih.gov/compound/chlorobenzene.

(4) National Library of Medicine. Compound Summary: 1_2 dichlorobenzene https://pubchem.ncbi.nlm.nih.gov/compound/1_2-Dichlorobenzene.

(5) Accudyne Test. Critical Surface Tension and Contact Angle with Water for Various Polymers. https://www.accudynetest.com/polytable_03.html.

(6) Alkhadra, M. A.; Root, S. E.; Hilby, K. M.; Rodriquez, D.; Sugiyama, F.; Lipomi, D. J. Quantifying the Fracture Behavior of Brittle and Ductile Thin Films of Semiconducting Polymers. Chem. Mater. 2017, 29, 10139-10149. https://doi.org/10.1021/acs.chemmater.7b03922.

(7) Kim, J. H.; Nizami, A.; Hwangbo, Y.; Jang, B.; Lee, H. J.; Woo, C. S.; Hyun, S.; Kim, T. S. Tensile Testing of Ultra-Thin Films on Water Surface. Nat. Commun. 2013, 4, 1-6. https://doi.org/10.1038/ncomms3520.

(8) Spano, F. C. The Spectral Signatures of Frenkel Polarons In. Acc. Chem. Res. 2010, 43 (3), 429-439. 